\title{
Correction to: Long non-coding RNA PXN- AS1 suppresses pancreatic cancer progression by acting as a competing endogenous RNA of miR-3064 to upregulate PIP4K2B expression
}

\author{
Jiayan Yan $^{1+}$, Yunxi $\mathrm{Jia}^{2+}$, Han Chen ${ }^{3}$, Wei Chen ${ }^{1}$ and Xiaoying Zhou ${ }^{3 *}$
}

\section{Correction to: J Exp Clin Cancer Res https://doi.org/10.1186/s13046-019-1379-5}

In the original publication of this manuscript [1], there are errors in Fig. 3. The authors declare that the identified errors do not change the results or conclusions of this paper.

The images of Fig. 3F (control group and miR-3064-KO-2 group) were mistakenly selected and used. The revised Fig. 3 is shown below.

In addition, scale bars are added into Figs. 3 and 7.

The authors apologize for the inconvenience caused to the readers.

\begin{abstract}
Author details
'Department of Biliary-Pancreatic Surgery, Renji Hospital, School of Medicine, Shanghai Jiaotong University, Shanghai 200127, China. ${ }^{2}$ Department of endoscopy of geriatric gastroenterology, First Affiliated Hospital of Nanjing Medical University, Nanjing 210029, China. ${ }^{3}$ Department of gastroenterology, First Affiliated Hospital of Nanjing Medical University, Nanjing 210029, China.
\end{abstract}

Published online: 07 May 2020

\section{Reference}

1. Yan, et al. Long non-coding RNA PXN-AS1 suppresses pancreatic cancer progression by acting as a competing endogenous RNA of miR-3064 to upregulate PIP4K2B expression. J Exp Clin Cancer Res. 2019;38:390.

The original article can be found online at https://doi.org/10.1186/s13046019-1379-5.

* Correspondence: zhouxiaoying@yahoo.com

${ }^{\dagger}$ Jiayan Yan and Yunxi Jia contributed equally to this work.

${ }^{3}$ Department of gastroenterology, First Affiliated Hospital of Nanjing Medical University, Nanjing 210029, China

Full list of author information is available at the end of the article

(c) The Author(s). 2020 Open Access This article is licensed under a Creative Commons Attribution 4.0 International License, which permits use, sharing, adaptation, distribution and reproduction in any medium or format, as long as you give appropriate credit to the original author(s) and the source, provide a link to the Creative Commons licence, and indicate if changes were made. The images or other third party material in this article are included in the article's Creative Commons licence, unless indicated otherwise in a credit line to the material. If material is not included in the article's Creative Commons licence and your intended use is not permitted by statutory regulation or exceeds the permitted use, you will need to obtain permission directly from the copyright holder. To view a copy of this licence, visit http://creativecommons.org/licenses/by/4.0/. The Creative Commons Public Domain Dedication waiver (http://creativecommons.org/publicdomain/zero/1.0/) applies to the data made available in this article, unless otherwise stated in a credit line to the data. 
A

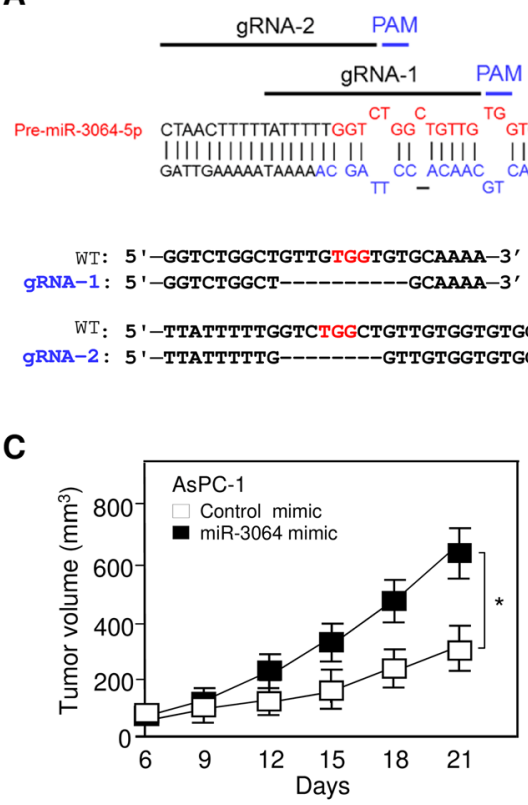

B

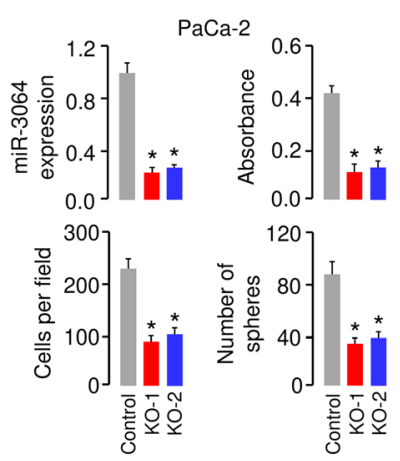

D

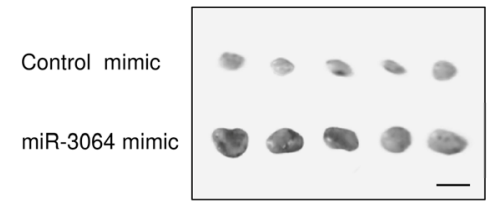

E

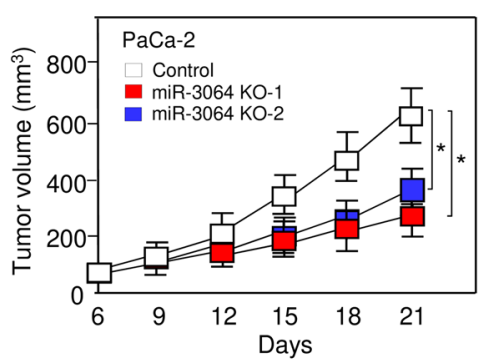

F

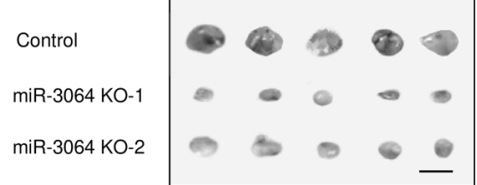

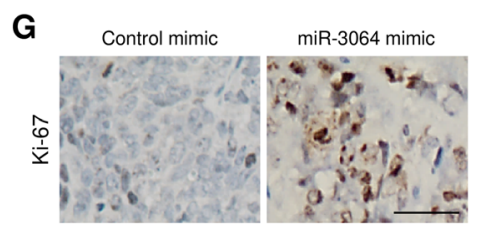

H

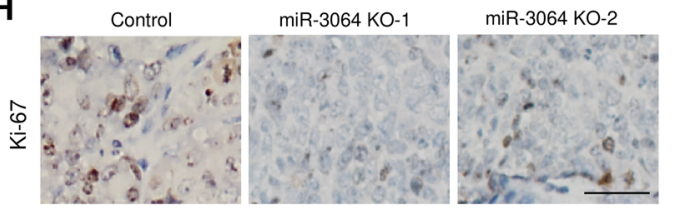

Fig. 3 Depletion of miR-3064 suppresses the aggressive phenotypes of PC cells in vitro and inhibits tumor growth in xenograft mouse models. a Schematic diagram of gRNAs targeting at miR-3064 locus (upper). DNA sequencing confirmed the deletions generated by CRISPR/Cas9 system in the miR-3064 locus (bottom). b CRISPR/Cas9 with designed gRNAs significantly reduced the expression of miR-3064, and suppressed the proliferation, invasion and sphere formation of PaCa-2 cells. c, d AsPC-1 cells were transfected with or without miR-3064 mimic, and injected into nude mice. Tumor growth rates (c) and images (d) of xenograft tumors were shown. e, $\mathbf{f}$ The miR-3064 knockout or control PaCa-2 cells were injected into nude mice, and tumor growth rate (e) and images (f) of xenograft tumors were shown. $\mathbf{g}, \mathbf{h}$ Immunohistochemical staining of Ki-67 in tumors derived from (c and $\mathbf{e}) .{ }^{*} P<0.05$ 
A

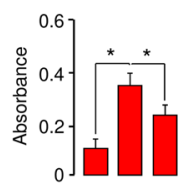

PXN-AS1 SiRNA-1 - + + PXN-AS1 SiRNA-1 -++

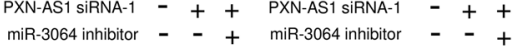

B

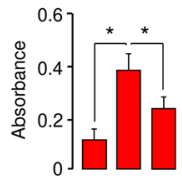

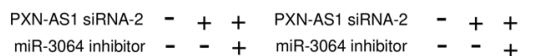

c

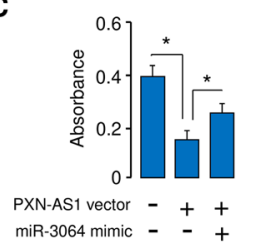

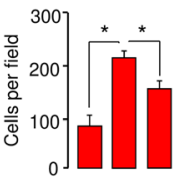

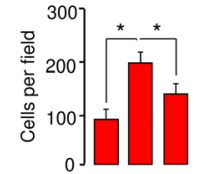

PXN-AS1 SiRNA-1 - + + $\begin{array}{lll}\text { PXN-AS1 SiRNA-1 } & + & + \\ \text { miR-3064 inhibitor }- & +\end{array}$

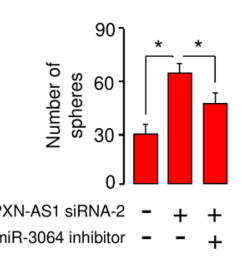

D
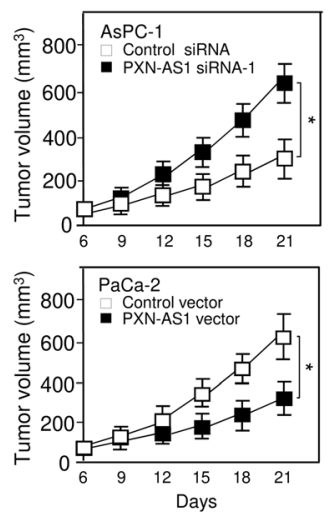

E

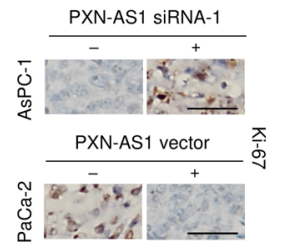

Fig. 7 PXN-AS1 suppresses PC cell proliferation, invasion and sphere formation partly through inhibiting miR-3064 expression. (a, b) Cell proliferation, invasion and sphere formation assays in AsPC-1 cells transfected with PXN-AS1 siRNA-1 (a), or PXN-AS1 siRNA-2 (b)), along with (or without) miR-3064 inhibitor. (c) Cell proliferation, invasion and sphere formation assays in PaCa-2 cells transfected with PXN-AS1 expression vector, along with (or without) miR-3064 mimic. (d) PC cells were transfected with PXN-AS1 siRNA-1 or PXN-AS1 expression vector as indicated, and then injected into nude mice. Tumor growth rates of xenograft tumor were shown. (e) Immunohistochemical staining of Ki-67 in tumors derived from $(\mathbf{d}) .{ }^{*} P<0.05$ 